\title{
Prevalence of hepatitis $B$ and hepatitis $C$ infections and their relationship to injectable drug use in a cohort of Sri Lankan prison inmates
}

\author{
M A Niriella ${ }^{1}$, A Hapangama ${ }^{2}$, H P D P Luke ${ }^{1}$, A Pathmeswaran ${ }^{3}$, K A L A Kuruppuarachchi $^{2}$, H J de Silva ${ }^{1}$
}

(Index words: Hepatitis B, Hepatitis C, injectable drug use, prevalence, prisoners)

\begin{abstract}
Introduction Prisoners are considered to be at high risk for Hepatitis B (HBV) and Hepatitis C (HCV) virus infections. This is attributed to intravenous drug use and high-risk sexual behaviour. There are no published studies on HBV and HCV among prison inmates or injecting drug users in Sri Lanka.

Objectives To determine prevalence of HBV and HCV infections, and their relationship to injectable drug use among Sri Lankan prisoners.

Methods We investigated 393 (median age 42 years (range 16 to 93 ); $82 \%$ males) randomly selected inmates of Mahara and Welikada prisons.

Results Though 167 (42.5\%) admitted drug abuse, only 17 $(4.3 \%)$ had ever used intravenous drugs. Twelve $(70.6 \%)$ of them reported sharing needles. One inmate was positive for HBsAg but was negative for HBV-DNA. Twenty seven $(6.9 \%)$ were positive for anti-HCV antibodies, of whom only $2(0.5 \%)$ were positive for HCV-RNA. None of the injecting drug users were positive for HBV-DNA or HCV-RNA.

Conclusions The prevalence of HBV and HCV infections as well as injecting drug use was very low among this cohort of Sri Lankan prison inmates.
\end{abstract}

Ceylon Medical Journal 2015; 60: 18-20

\section{Introduction}

The global prevalence of hepatitis B (HBV) and hepatitis $\mathrm{C}(\mathrm{HCV})$ infections vary in different geographical areas. There are no island-wide studies to determine prevalence in Sri Lanka, but studies involving different population groups are available. Community surveys and large studies among blood donors and pregnant females employing serological tests have found a low prevalence for both Hepatitis B $(<2 \%)$ and Hepatitis $\mathrm{C}(<1 \%)$ [1]. The prevalence of HCV-RNA-positivity among blood donors has also been found to be low [2]. This is despite the country being situated in a geographical region considered to be of intermediate endemicity for these infections.

Prisoners are considered to be at high risk for HBV and $\mathrm{HCV}$, and this is attributed to intravenous drug use and high-risk sexual behaviour. The age-standardised prevalence of HBsAg among Australian prisoners was $2.3 \%$, and anti-HCV was $29 \%$; it has decreased over time and the reduction coincided with a decrease in prison entrants reporting injecting drug abuse $(58.3 \%$ in 2004 vs. $45.3 \%$ in 2010 ); among injecting drug users, the prevalence of anti-HCV was 57.2\% [3]. Among substance dependent patients admitted to a tertiary hospital in India, $66.1 \%$ of injecting drug users were $\mathrm{HCV}$ positive and $5.1 \%$ were HBsAg positive [4]. There are no comparable published studies on $\mathrm{HBV}$ and $\mathrm{HCV}$ among prison inmates or injecting drug users in Sri Lanka.

We carried out a cross sectional study inMahara and Welikada prisons (among the largest prisons in Sri Lanka) to determine prevalence of $\mathrm{HBV}$ and $\mathrm{HCV}$ infections among inmates, and their relationship to injecting drug use.

\section{Methods}

We sampled 396 prisoners which consisted of $10 \%$ of the total inmates of Mahara and Welikada prisons. Inmates who were over the age of 18 , were recruited randomly from the prison registers. Data was collected using an interviewer administered, structured questionnaire by trained research assistants. Substance use and abuse were defined according to the ICD-10 Classification of Mental and Behavioural Disorders. All participants were questioned for past and present injecting drug use. Two $5 \mathrm{ml}$ samples of blood were obtained for screening and conformation of $\mathrm{HBV}$ and HCV. The sample for screening was transported to the Medical Research Institute (MRI) within one hour of collection and the sample for conformation was stored at $-80^{\circ} \mathrm{C}$ to be used to test individuals who were positive at screening. Screening for $\mathrm{HBV}$ and $\mathrm{HCV}$ was performed using Hepatitis B surface antigen ( $\mathrm{HBs} \mathrm{Ag}$ ) and Anti-HCV antibodies (anti-HCV) using CTK BIOTECH ELISA kits. Confirmation of active infection in those positive

Departments of Medicine ${ }^{1}$, Psychiatry ${ }^{2}$ and Public Health ${ }^{3}$, Faculty of Medicine, University of Kelaniya, Sri Lanka.

Correspondence: MAN, e-mail: <maduniln@yahoo.co.uk>. Received 14 August and revised version accepted 7 November 2014. Competing interests: none declared. 
for screening was by HBV-DNA and HCV-RNA assays using quantitative reverse transcription-polymerase chain reaction (RT-PCR).

Ethical approval for this study was obtained from the Ethics Review Committee of the Faculty of Medicine, University of Kelaniya. Since this was a vulnerable population, no prison officials were involved in the data gathering process, and informed consent and complete confidentiality of the divulged information was ensured in all cases.

\section{Results}

Of the 396 inmates, data were complete only for 393 (median age 42 years (range 16 to 93 ); 82\% males) (Table 1).

Though 167 (42.5\%, 143 males) inmates admitted drug abuse, only 17 (4.3\%; 15 males) had ever used the intravenous route. Of the 17 who admitted to injecting drugs, $12(70.6 \%)$ reported sharing needles. Cannabis, Kerela ganja, cocaine, heroin and other opioids use were also reported by the inmates.

One inmate was positive for $\mathrm{HBsAg}$ but was negative for HBV-DNA. He was a non-injecting drug user. Twenty seven $(6.9 \%, 24$ males) were positive for anti-HCV antibodies, of whom only $2(0.5 \%$; both males and non-injecting drug abusers) were positive for HCV-RNA.Twelve (8\%) non-injecting drug users and 15 $(6.6 \%)$ non-drug users were anti-HCV positive. None of the injecting drug users were positive for HBsAg, antiHCV, HBV-DNA or HCV-RNA.

\section{Discussion}

The prevalence of HBV and HCV infections, as well as injecting drug use was low among this cohort of Sri Lankan prison inmates. These findings are compatible with previously reported low prevalence for both Hepatitis $\mathrm{B}(<2 \%)$ and Hepatitis $\mathrm{C}(<1 \%)$ infections among different populations in Sri Lanka [1]. The low rate of $\mathrm{HCV}$ infection and the near absence of HBV infection in our study population may reflect the low rate of these infections in the country as well as the very low rates of injecting drug use.

The prevalence of HBV and HCV infections varies in different Asian geographical regions. China is the only country in Asia that was classified as high endemic area with prevalence of $7-20 \%$ for HBV infection. Countries with intermediate endemicity for HBV infection include India, Korea, Taiwan, and Thailand, and those with low endemicity include Japan, Pakistan, Singapore, and Malaysia with $0.2-1.9 \%$ prevalence. Prevalence of HCV in Asia ranges from 2.15-3.9\% [5]. The present study, conducted among a presumed 'high risk population', further confirms the low endemicity of both HBV and HCV infections in Sri Lanka.

A person is considered to have evidence of $\mathrm{HCV}$ infection only after an anti-HCV screening-test-positive result has been verified by a more specific serological test or a nucleic acid test (NAT) [6]. Confirmation of active $\mathrm{HCV}$ infection in anti-HCV positive inmates by RT-PCR in our study fulfills this requirement. The relatively high screening positive rate (anti-HCV positive) of $6.9 \%$ for $\mathrm{HCV}$ with low confirmed (HCV-RNA positive) rate of only $0.5 \%$ may indicate false positivity of the screening test. Such false positivity arises in the presence of previous infections with other RNA viruses, and is a common phenomenon in low prevalence countries [7].

Anti-HCV and HCV-RNA was negative among all injecting drug users, most of whom shared needles, while it was positive in a few who claimed to be non-injecting drug users. This was surprising. A possible explanation is the unreliability of the information provided regarding the route of use by the inmates who claimed to be noninjecting drug users. Although our findings are based on a relatively small sample, results are very different from those of studies from many developed countries that show prison inmates are at high risk for $\mathrm{HBV}$ and $\mathrm{HCV}$ infection with the main risk factor being injectable drug use [3]. A major limitation of this study was the lack of detailed information on unprotected sex which is a common risk factor for acquiring $\mathrm{HBV}$ and $\mathrm{HCV}$ infections.

Table 1. Summary of the results

\begin{tabular}{lccc}
\hline & Male $(n=325)$ & Female $(n=68)$ & Total $(n=393)$ \\
\hline Drug abuse & $143(44 \%)$ & $24(37.5 \%)$ & $167(41.7 \%)$ \\
IV drug abuse & $15(4.6 \%)$ & $2(2.9 \%)$ & $17(4.3 \%)$ \\
Hep B screening positive & $1(0.3 \%)$ & 0 & $1(0.25 \%)$ \\
Hep B DNA positive & 0 & 0 & 0 \\
Hep C screening positive & $24(7.4 \%)$ & $3(4.4 \%)$ & $27(6.9 \%)$ \\
Hep C RNA positive & $2(0.6 \%)$ & 0 & $2(0.5 \%)$ \\
\hline
\end{tabular}


In conclusion, in a presumed high risk population of Sri Lankan prisoners, the prevalence of HBV and $\mathrm{HCV}$ infections and injecting drug use was very low. We could not find a relationship between these infections and intravenous drug use as both $\mathrm{HBV}$ and $\mathrm{HCV}$ infections as well as intravenous drug use were of low prevalence.

\section{Declaration of Interest}

There are no conflicts of interest.

\section{References}

1. de Silva HJ, Fonseka MMD. Seroepidemiology of Hepatitis C in SAARC countries. In: Sarin SK, Okuda K (Eds). Hepatitis B and C: from Carrier to Cancer. New Delhi: Harcourt (India) / Elsevier Science, 2002: 187-200.
2. Manamperi A, Nugawela P, Gunawardene NS et al. RNA positivity rates among anti-HCV reactive blood donors in Sri Lanka: A preliminary study. Indian J of Med Microbiol 2010; 28: 264-5.

3. Reekie JM, Levy MH, Richards AH et al. Trends in HIV, hepatitis B and hepatitis C prevalence among Australian prisoners - 2004, 2007, 2010. Med J Aust 2014; 200: 277-80.

4. Chalana H, Singh H, Sachdeva JK, Sharma S.Seroprevalence of human immunodeficiency virus, hepatitis B surface antigen, and hepatitis $\mathrm{C}$ in substance dependents admitted in a tertiary hospital at Amritsar, India. Asian J Psychiatr 2013; 6: 552-5.

5. Zidan A, Scheuerlein H, Schüle S, Settmacher U, Rauchfuss F. Epidemiological pattern of hepatitis $\mathrm{B}$ and hepatitis $\mathrm{C}$ as etiological agents for hepatocellular carcinoma in Iran and worldwide. Hepatitis Monthly 2012; 12 (10 HCC): e6894.

6. Pawlotsky JM. Use and interpretation of virological tests for hepatitis C. Hepatology 2002; 36(5 Suppl 1): S65-S73.

7. Sakugawa H, Nakasone H, Nakayoshi $\mathrm{T}$ et al. High proportion of false positive reactions among donors with anti-HCV antibodies in a low prevalence area. J Med Virol 1995; 46: 334-8. 